\title{
Identification of an interferon- $\gamma$-responsive element of a class II major histocompatibility gene in rat type 1 astrocytes
}

\author{
Harold Moses ${ }^{1}$, Atsushi Sasaki ${ }^{2, *}$ and Jenny P.-Y. Ting ${ }^{1,2,3}$ \\ ${ }^{1}$ Curriculum in Neurobiology, ${ }^{2}$ Lineberger Cancer Research Center, and ${ }^{3}$ Department of Microbiology-Immunology, University of \\ North Carolina, Chapel Hill, NC 27599, U.S.A.
}

(Received 11 September 1990)

(Revised, received 20 November 1990)

(Accepted 21 November 1990)

Key words: Astrocyte, type 1; Transfection; Class II major histocompatibility complex; Interferon- $\gamma$; Gene regulation

\section{Summary}

Interferon- $\gamma($ IFN- $\gamma)$ has been shown to induce class II major histocompatibility complex (MHC) antigens on several cell types. Previous analysis of cell lines including a glioblastoma multiforme line by our laboratory has mapped an IFN- $\gamma$-responsive element to the upstream - 141 to -109 base pair (bp) region of the DRA promoter. Using deletion mutants, this report shows that this same general region $(-135$ to $-109 \mathrm{bp})$ is important for IFN- $\gamma$ induction in two other human glioma lines and more importantly in primary astrocytes. We have confirmed that this regulatory region of the HLA-DRA gene is necessary for IFN- $\gamma$ inducibility in astrocytes using a substitution mutant. Sequences beyond -135 bp do not appear to have any additional positive or negative elements.

\section{Introduction}

Class II major histocompatibility complex (MHC) genes encode for proteins that have a central role in the immune response. Due primarily to the presence of the blood-brain barrier, the central nervous system was believed to be an immunologically privileged site. However, recent studies have demonstrated class II MHC antigens are present within the brain (Hickey et al., 1985;

\footnotetext{
Address for correspondence: Harold Moses, Rm. 209 Lineberger Cancer Research Center CB 7295, University of North Carolina, Chapel Hill, NC 27599-7295, U.S.A.

* Present address: Department of Pathology, Gunma University School of Medicine, Gunma, Japan.
}

Male et al., 1987). More importantly, MHC class II proteins on glial cells are elevated in a number of pathological conditions (McGeer et al., 1988). In vitro studies have shown that class II bearing astrocytes can act as antigen presenting cells for encephalitogenic T-cells (Fontana et al., 1984). In culture, interferon- $\gamma(\mathrm{IFN}-\gamma)$ is a potent inducer of class II antigen expression on type 1 astrocytes (Wong et al., 1984).

Previous work from our laboratory had identified cis-acting DNA sequences responsible for IFN- $\gamma$ inducibility of MHC class II gene expression (Basta et al., 1987, 1988). These experiments were done using a glioblastoma multiforme line. In this report, we extended previous work and determined the activity of this IFN- $\gamma$-inducible responsive region in two other glioma cell lines. 
Most significantly, the IFN- $\gamma$-responsive region was also delineated in type 1 astrocytes by DNAmediated gene transfer.

Conserved upstream sequences have been well characterized in the DRA promoter (Fig. 1). They are responsible for the transcriptional regulation of this coordinately regulated gene in a tissue- and cell type-specific manner (reviewed in Sullivan et al., 1987; Benoist and Mathis, 1990). These conserved elements include $\mathrm{W}, \mathrm{X}$ and $\mathrm{Y}$ from $5^{\prime}$ to $3^{\prime}$ respectively (reviewed in Benoist and Mathis, 1990). X and $Y$ have been shown to be functionally important in transfection assays (Dorn et al., 1987; Sloan and Boss, 1988; Sherman et al., 1989). They appear to be positive control elements for class II expression in different cell types (Dedrick and Jones, 1990; Finn et al., 1990), and to play a role in IFN- $\gamma$ inducibility in a HeLa cell line (Tsang et al., 1990). The $\mathrm{W}$ box is located from -135 to $-118 \mathrm{bp}$ of the DRA regulatory region. Several laboratories, including our own, have demonstrated that this element is important in IFN- $\gamma$ inducibility (Basta et al., 1988; Tsang et al., 1990). However, to date the analysis of IFN- $\gamma$-responsive elements has not been performed using primary, nontransformed cells. This is the first report of such an analysis.

\section{Materials and methods}

Primary glial cultures. Sprague-Dawley rats (2 days postnatal at the latest) were used to prepare mixed brain cell cultures. Cerebral cortical tissue was used as previously described (McCarthy and de Vellis, 1980). Cells were grown in Dulbecco's modified Eagle's medium (DMEM) supplemented with glucose $(0.9 \%)$, L-glutamine $(2 \mathrm{mM})$, sodium bicarbonate, penicillin $(50 \mathrm{IU} / \mathrm{ml})$, streptomycin $(50 \mu \mathrm{g} / \mathrm{ml})$ plus fetal calf serum (FCS) $(10 \% \mathrm{v} / \mathrm{v}$, Gibco). The cultures became confluent on approximately day 14 and type 1 astrocytes were purified by a differential adhesion technique (Sasaki et al., 1989). Cells were prepared for transfection by trypsinization.

Glioma lines. U105-MG (Takiguchi et al., 1985) and D54-MG (Wikstrand et al., 1984) are two glioblastoma multiforme lines that are induced to express class II MHC molecules with IFN- $\gamma$ treatment. These cells were maintained in
McCoy's 5A media supplemented with $10 \%$ FCS, $2 \mathrm{mM}$ L-glutamine, and $0.05 \mathrm{mg} / \mathrm{ml}$ gentamicin.

Recombinant rat IFN- $\gamma(r I F N-\gamma)$. Rat rIFN- $\gamma$ was purchased from Amgen (Thousand Oaks, CA, U.S.A.). A stock solution was made in phosphatebuffered saline (PBS) at $2 \times 10^{4} \mathrm{U} / \mathrm{ml}$. Astrocytes were treated with $\mathrm{rIFN}-\gamma(50-100 \mathrm{U} / \mathrm{ml})$ for 2 days prior to the CAT assay.

Plasmids. Plasmids containing $5^{\prime}$ deletions ( $5^{\prime} \Delta-1028$ and $5^{\prime} \Delta-267$ ) were previously described (Basta et al., 1988). They contain DRA promoter sequences from -1028 and $-267 \mathrm{bp}$, respectively, to +27 bp linked to a chloramphenicol acetyltransferase (CAT) gene. The plasmids in the deletion series $5^{\prime} \Delta-210$ to $5^{\prime} \Delta-109$ were derived from pDRA1000 as described (Sherman et al., 1987). They contain 210 and 109 bp of DRA sequence $5^{\prime}$ of the transcription start site respectively.

A substitution mutant was made by randomly mutating the region of a pDRA-CAT construct from -141 to $-109 \mathrm{bp}$. This construct is known as pMut-IRE. The wild-type control is denoted as pWT-IRE. These were previously described in detail (Basta et al., 1988). The negative (pD164-2) and positive (pSV2CAT) control plasmids have been described (Basta et al., 1987).

Transfection. Transfections were performed by electroporation using a Bio-Rad gene pulser. $5 \mu \mathrm{g}$ of plasmid DNA were used per transfection. $3 \times$ $10^{6}$ cells in $300 \mu \mathrm{l}$ of medium were pulsed at 200 $\mathrm{mV}$ at a capacitance setting of $960 \mu \mathrm{F}$. The cells were plated into $10 \mathrm{ml}$ of complete medium and allowed to adhere before the addition of IFN- $\gamma$.

CAT assay. CAT activity was assayed according to the method of Gorman et al. (1982). Quantitative measurements were obtained by cutting out both the acetylated and nonacetylated products on thin-layer chromatography (TLC) plates and measuring radioactivity in a scintillation counter. Percent acetylation is calculated as acetylated counts / (acetylated counts + nonacetylated counts) $\times 100 \%$.

\section{Results and discussion}

Description of a nested series of $5^{\prime} p D R A-C A T$ deletion mutants. A series of deletion mutants encoding the $5^{\prime}$ regulatory region of the DRA 


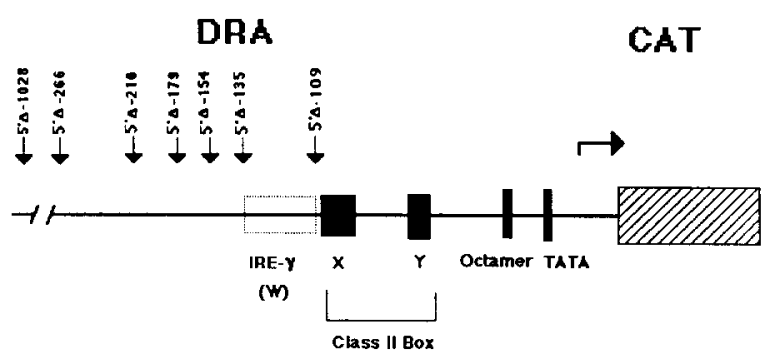

Fig. 1. Promoter region of the HLA-DRA gene and a map of the $5^{\prime}$ deletion mutants used in transfection experiments. The DRA transcription start site is marked by the bent arrow. The hatched box represents the CAT gene. Solid boxes represents known cis-acting elements necessary for basal transcription (Sherman et al., 1987). The open box shows the location of the IFN- $\gamma$-responsive element (IRE- $\gamma$ ) transfected into gliomas and astrocytes.

gene were made to characterize important sequence for IFN- $\gamma$ inducibility (Fig. 1). These constructs vary in length from -1028 to $-109 \mathrm{bp}$ of the DRA upstream sequence and are placed 5' of the indicator gene CAT in the parent plasmid, $\mathrm{pD}$ 164-2 (Basta et al., 1987). All of the constructs contain a CAAT box, a TATA box and a transcriptional start site. The class II boxes $(\mathrm{X}+\mathrm{Y})$ are also present in these constructs.

$D R A$ regulatory sequences important for rIFN$\gamma$-induced gene expression in gliomas. The deletion mutants shown in Fig. 1 were used to transfect two glioma lines (U105-MG and D54-MG) that express class II MHC antigens upon IFN- $\gamma$ treatment. These experiments are important because previously we only analyzed one glioma line for an IFN- $\gamma$-responsive element in the DRA gene. CAT activity was determined by measuring the ability of transfected cell extracts to acetylate the substrate $\left[{ }^{14} \mathrm{C}\right]$ chloramphenicol. Fig. 2 shows a representative CAT assay using a glioblastoma multiforme line designated D54-MG. Similar results were obtained with U105-MG (data not shown). In both cell lines, IFN- $\gamma$ inducibility was only seen when the construct $5^{\prime} \Delta-135$ was utilized. The $5^{\prime} \Delta-109$ construct showed little or no induction with IFN- $\gamma$ treatment. Sequences further upstream of $-135 \mathrm{bp}$ did not appear to contain any additional IFN- $\gamma$-responsive elements. These data indicate that the region between -135 and -109 $\mathrm{bp}$ is necessary for IFN- $\gamma$ induction in two glioma lines. These data are consistent with results found using another glioma line (Basta et al., 1988).

$D R A$ regulatory sequences important for $r I F N$ $\gamma$-induced gene expression in astrocytes. Table 1 is a summary of transfection experiments done using the deletion mutants in type 1 astrocytes. Deletion constructs of the human HLA-DRA promoter were transfected into rat astrocytes because the class II MHC promoter sequence in the rat has not been characterized. For each construct, at least four independent experiments were done. The fold induction upon IFN- $\gamma$ treatment was calculated by dividing the percent acetylation value of an IFN- $\gamma$-treated culture by the percent acetylation value of an untreated culture. The construct containing only the class II boxes and not any additional $5^{\prime}$ sequences was not inducible with IFN- $\gamma$ treatment $\left(5^{\prime} \Delta-109\right)$. However, the $5^{\prime} \Delta-135$ plasmid elicited a 4.33 times increase over basal levels with IFN- $\gamma$ treatment. Furthermore, sequences upstream of $-135 \mathrm{bp}$ did not affect IFN- $\gamma$

\section{D54-MG}

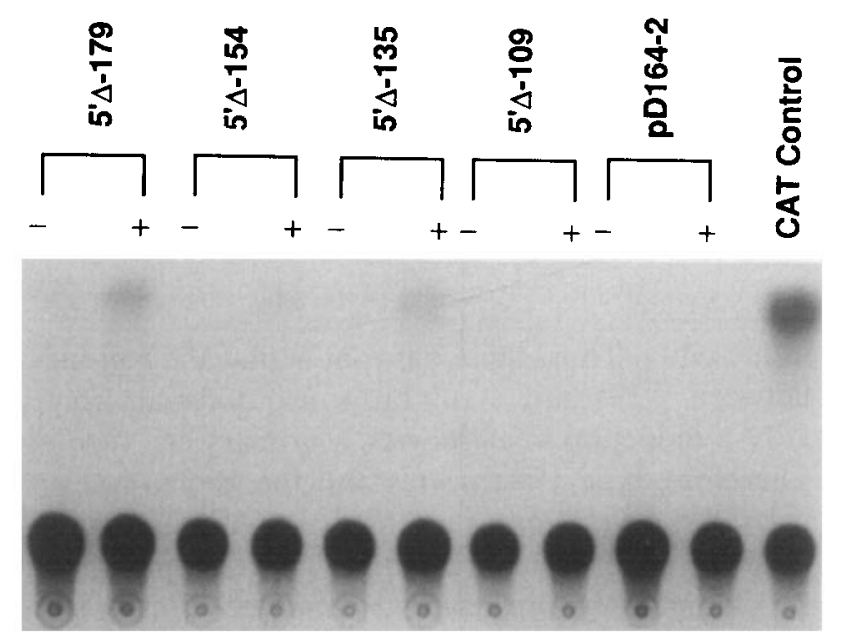

Fig. 2. IFN- $\gamma$ induction of DRA $S^{\prime}$ deletion mutants in a human glioma line, D54-MG. The deletion constructs were assayed for CAT activity with or without IFN- $\gamma$-treatment. pD164-2 contains the CAT gene without any DRA promoter sequence. Transient transfection assays were performed. Each construct was transfected in the cell line at least 4 times and a representative result is shown. The symbol $(-)$ denotes no IFN $-\gamma$ treatment. The symbol $(+)$ indicates that cells were treated with IFN- $\gamma$. 


\section{TABLE 1}

IFN- $\gamma$ INDUCTION OF PROMOTER ACTIVITY OF PDRA-CAT DELETION MUTANTS IN TYPE 1 ASTROCYTES

Percent acetylation was calculated by comparing the amount of radioactivity in the acetylated product/radioactivity in the acetylated + nonacetylated products. The values shown for percent acetylation are from a representative experiment. The fold induction values are from four experiments and are calculated as the ratio of percent treated vs. percent untreated. This ratio demonstrates the IFN- $\gamma$ inducibility of the various deletion constructs. The negative control, pD164-2, contains the CAT gene without DRA promoter sequence and had no induction with IFN- $\gamma$ treatment. Another control was pSV2CAT which contains the strong SV40 promoter that is not IFN- $\gamma$ inducible.

\begin{tabular}{llrl}
\hline $\begin{array}{l}\text { pDRA-CAT } \\
\text { construct }\end{array}$ & $\begin{array}{l}\text { IFN- } \gamma \\
\text { treatment }\end{array}$ & Acetylation (\%) & $\begin{array}{l}\text { Fold } \\
\text { induction }\end{array}$ \\
\hline $5^{\prime} \Delta-109$ & - & 2.0 & 1 \\
& + & 2.4 & \\
$5^{\prime} \Delta-135$ & - & 11.9 & $4.33 \times$ \\
& + & 41.2 & \\
$5^{\prime} \Delta-154$ & - & 2.2 & $4.62 \times$ \\
& + & 10.6 & $3.64 \times$ \\
$5^{\prime} \Delta-179$ & - & 0.7 & \\
& + & 2.4 & $5.78 \times$ \\
$5^{\prime} \Delta-210$ & - & 2.3 & $5.69 \times$ \\
& + & 9.1 & \\
$5^{\prime} \Delta-266$ & - & 3.0 & $4.60 \times$ \\
& + & 7.9 & \\
$5^{\prime} \Delta-1028$ & - & 1.9 & $<1$ \\
& + & 9.9 & \\
pD164-2 & - & 1.0 & \\
& + & 0.4 & \\
pSV2CAT & - & 82.6 & \\
& + & 76.2 & \\
\hline
\end{tabular}

inducibility. Thus, these data show that the region between -135 and $-109 \mathrm{bp}$ is also necessary for IFN- $\gamma$ induction in astrocytes, a primary cell type. Therefore, type 1 astrocytes and the glioma lines use the same or similar mechanism to induce class II MHC gene expression with IFN- $\gamma$ treatment.

Loss of IFN- $\gamma$ inducibility by random mutation of the -141 to $-109 \mathrm{bp}$ region. To further define the role of the -135 to -109 bp region, a substitution mutant inclusive of this region (pMUTIRE) was transfected into type 1 astrocytes. A wild-type control construct, pWT-IRE, was also used. Random mutagenesis of this region addresses a potential problem of $5^{\prime}$ deletion mutants, whereby the spacing between plasmid DNA and the sequence of interest is altered. These differences may contribute to false levels of transcription due to cryptic start sites. As seen in Fig. 3, pWT-IRE induced CAT expression to similar levels as observed with the deletion construct, $5^{\prime} \Delta-135$. However, mutations in pMUT-IRE abolished IFN- $\gamma$-inducible CAT expression. This confirms the importance of this region in IFN- $\gamma$ regulated DRA gene expression.

The mechanism by which IFN- $\gamma$ induces class II antigen expression is not clear. Different cell lines have been shown to use various second messengers to mediate IFN- $\gamma$ inducibility (Jones et al., 1988; Rosa et al., 1988). Therefore, we believe that it is important to examine primary cell types to understand the precise role of IFN- $\gamma$ induction in a more physiologically significant model. Since class II MHC antigen expression has been correlated to autoimmune and neurodegenerative events in the nervous system (McGeer et al., 1988), defin-
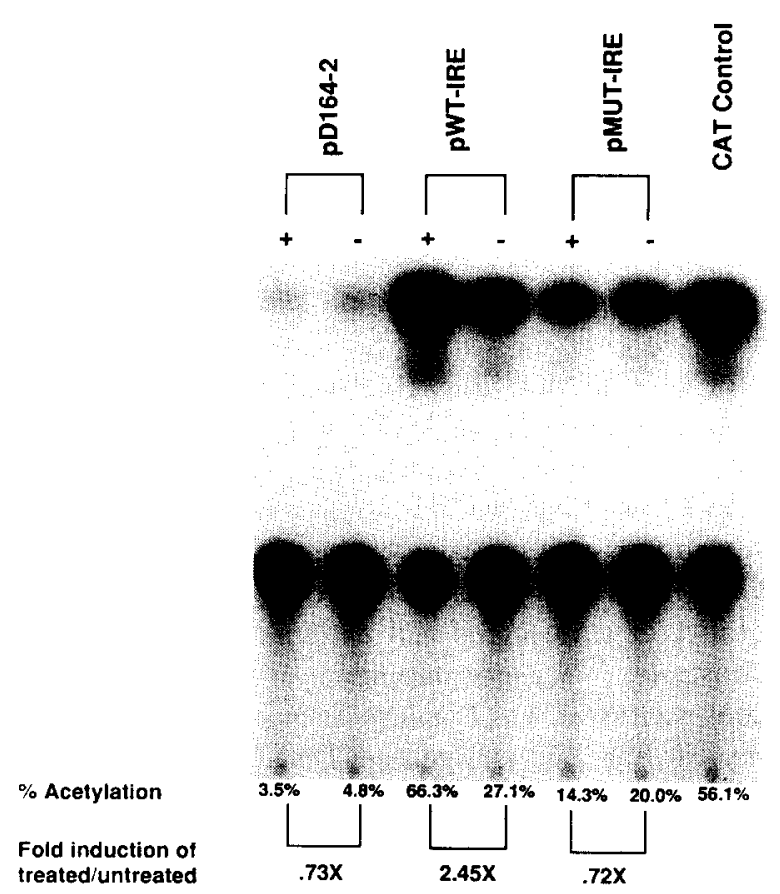

Fig. 3. Loss of IFN- $\gamma$ inducibility by substitution mutagenesis in the -141 to $-109 \mathrm{bp}$ region. The pMUT-IRE- $\gamma$ construct was randomly mutated from -141 to $-109 \mathrm{bp}$ and the pWT-IRE- $\gamma$ construct is a wild-type control. pD164-2 contains the CAT gene without any DRA promoter sequence. Transient transfection assays were performed using type 1 astrocytes and a representative result is shown. 
ing the mechanism of class II induction on astrocytes is important.

In this report, we have examined the role of regulatory sequences in mediating the effects of IFN- $\gamma$ treatment on DRA gene expression. Deletion and substitution mutagenesis were performed and confirmed the importance of the -135 to $-109 \mathrm{bp}$ region in IFN- $\gamma$ induction. This region coincides with the $\mathrm{W}$ region which is also important for basal transcription in several cell types (Cogswell et al., 1990; Tsang et al., 1990). In this report, both cell lines and primary cells utilize an identical region for IFN- $\gamma$ response. Thus, the glioma lines serve as a useful model for molecular events that may be occurring in vivo.

There have been reports describing microglia cells as another major cell type that express class II antigens in vitro (Frei et al., 1987; Suzumura et al., 1987; Sasaki et al., 1989). It is of interest to understand if microglia cells utilize the same sequence in the HLA-DRA promoter for IFN- $\gamma$ induction. This is important because class II MHC appears to be differentially regulated in astrocytes vs. microglia. As an example, treatment with cAMP analogues down-regulates class II expression on type 1 astrocytes but not microglia (Sasaki et al., 1990). Using the transfection procedure described here, it is now feasible to decipher the molecular basis for class II MHC gene regulation in different glias.

\section{Acknowledgements}

This work is supported by a National Multiple Sclerosis Society grant (RG 1785-B) and an Alzheimer's Society grant (PRG-89-148) to J.P.-Y. Ting. We thank Dr. John Cogwell for a review of this report and Ms. Jane Radford for secretarial and graphical assistance.

\section{References}

Basta, P.V., Sherman, P.A. and Ting, J.P.-Y. (1987) Identification of an IFN- $\gamma$ responsive region $5^{\prime}$ of the human histocompatibility leukocyte antigen DRA chain gene which is active in human glioblastoma multiform lines. J. Immunol. $138,1275-1280$.
Basta, P.V., Sherman, P.A. and Ting, J.P.-Y. (1988) Detailed delineation of an interferon- $\gamma$-responsive element important in human HLA-DRA gene expression in a glioblastoma multiform line. Proc. Natl. Acad. Sci. U.S.A. 85, 8618-8622.

Benoist, C. and Mathis, D. (1990) In: W. Paul (Ed.), Annual Review of Immunology, Vol. 8, Annual Reviews, Palo Alto, CA, pp. 681-715.

Cogswell, J.P., Basta, P.V. and Ting, J.P.-Y. (1990) X-box binding protein positively and negatively regulate transcription of the HLA-DRA gene through interaction with discrete upstream $\mathrm{W}$ and $\mathrm{V}$ elements. Proc. Natl. Acad. Sci. U.S.A. 87, 7703-7707.

Dedrick, R.L. and Jones, P.P. (1990) Sequence elements required for activity of a murine major histocompatibility complex class II promoter bind common and cell-typespecific nuclear factors. Mol. Cell. Biol. 10, 593-604.

Dorn, A., Durand, B., Marfing, G., LeMeur, M., Benoist, C. and Mathis, D. (1987) Conserved major histocompatibility complex class II boxes $-\mathrm{X}$ and $\mathrm{Y}-$ are transcriptional control elements and specifically bind nuclear proteins. Proc. Natl. Acad. Sci. U.S.A. 84, 6249-6253.

Finn, P.W., Kara, C.J., Douham, III, J., Van, T.T., Folsom, V. and Glimcher, L.H. (1990) Interferon- $\gamma$ regulates binding of two nuclear protein complexes in a macrophage cell line. Proc. Natl. Acad. Sci. U.S.A. 87, 914-918.

Fontana, A., Fierz, W. and Wekerle, H. (1984) Astrocytes present myelin basic protein to encephalitogenic T-cell lines. Nature 307, 273-276.

Frei, K., Siepl, C., Groscurth, P., Bodmer, S., Schwerdel, C. and Fontana, A. (1987) Antigen presentation and tumor toxicity by interferon- $\gamma$ treated microglia cells. Eur. J. Immunol. 17, 1271-1278.

Gorman, C.M., Moffat, L. and Howard, B.H. (1982) Recombinant genomes which express chloramphenicol acetyltransferase in mammalian cells. Mol. Cell. Biol. 2, 1044-1051.

Hickey, W.F., Osborn, J.P. and Kirby, W.M. (1985) Expression of la molecules by astrocytes during acute experimental allergic encephalomyelitis in the Lewis rat. Cell. Immunol. 91, 528-535.

Jones, P.P., Ramani, A.A., Freun, Y.R., Pavlath, G.K. and Zimmer, T. (1986) In: B. Cinader and R.G. Miller (Eds.), Progress in Immunology, Vol. 6, Academic Press, New York, pp. 458-468.

Male, D.K., Pryce, G. and Hughes, C.C.W. (1987) Antigen presentation in brain: MHC induction on brain endothelium and astrocytes compared. Immunology 60, 453-459.

McCarthy, K.D. and de Vellis, J. (1980) Preparation of separate astroglial and oligodendroglial cell cultures from rat cerebral tissue. J. Cell Biol. 85, 890-902.

McGeer, P.L., Itagaki, S. and McGeer, E.G. (1988) Expression of the histocompatibility glycoprotein HLA-DR in neurological disease. Acta Neuropathol. 76, 550-557.

Rosa, F.M. and Fellous, M. (1988) Regulation of HLA-DR gene by IFN- $\gamma$ transcriptional and post-transcriptional control. J. Immunol. 140, 1660-1664.

Sasaki, A., Levinson, S.W. and Ting, J.P.-Y. (1989) Comparison and quantitation of Ia antigen expression on cultured macroglia and ameboid microglia from Lewis rat cerebral 
cortex: analyses and implications. J. Neuroimmunol. 25 , 63-74.

Sasaki, A., Levinson, S.W. and Ting, J.P.-Y. (1990) Differential suppression of interferon- $\gamma$-induced Ia antigen expression on cultured rat astroglia and microglia by second messengers. J. Neuroimmunol. 29, 213-222.

Sherman, P.A., Basta, P.V. and Ting, J.P.-Y. (1987) Upstream DNA sequences required for tissue-specific expression of the HLA-DR $\alpha$ gene. Proc. Natl. Acad. Sci. U.S.A. 84, 4254-4258.

Sherman, P.A., Basta, P.V., Moore, T.L., Brown, A.M. and Ting, J.P.-Y. (1989) Class II box consensus sequences in the HLA-DRA gene: transcriptional function and interaction with nuclear proteins. Mol. Cell. Biol. 9, 50--56.

Sloan, J.H. and Boss, J.M. (1988) Conserved upstream sequences of human class II major histocompatibility genes enhances expression of class II genes in wild-type but not mutant B-cell lines. Proc. Natl. Acad. Sci. U.S.A. 85, 81868190.

Sullivan, K.E., Calman, A.F., Nakanishi, M., Tsang, S.Y., Wang, Y. and Peterlin, B.M. (1987) A model for the transcriptional regulation of MHC class II genes. Immunol. Today 8, 289-293.
Suzumura, A., Mezitiz, S.G.E., Gonatas, N.K. and Silberberg, D.H. (1987) MHC antigen expression on bulk isolated macrophage-microglia from newborn mouse brain: induction of Ia antigen expression by $\gamma$-interferon. J. Neuroimmunol. 15, 263-278.

Takiguchi, M., Ting, J.P.-Y., Buessow, S.C., Boyer, C., Gillespie, V. and Frelinger, J.A. (1985) Response of glioma cells to interferon-gamma: increase in class II RNA, protein and mixed lymphocyte reaction-stimulating ability. Eur. J. Immunol. 15, 809-814.

Tsang, S.Y., Nakanishi, M. and Peterlin, B.M. (1990) Mutational analysis of the DRA promoter: cis-acting sequences and trans-acting factors. Mol. Cell. Biol. 10, 711-719.

Wikstrand, C.J., Bigner, S.H. and Bigner, D.D. (1984) Characterization of three restricted specificity monoclonal antibodies raised against the human glioma cell line D-54 MG. J. Neuroimmunol. 6, 169-186.

Wong, G.H.W., Bartlett, P.F., Clark-Lewis, I., Battye, F. and Schrader, J.W. (1984) Inducible expression of H-2 and Ia antigens on brain cells. Nature $310,688-691$. 